\title{
Predicting the Resilience of the Health Care System to New Arrivals: The Case of the Public Health System of Turkey
}

\author{
Ilhan Can Ozen ${ }^{1,2, *}$ and Berna Tuncay ${ }^{3}$ \\ ${ }^{1}$ Takemi Program-Department of Global Health and Population, Harvard University, Cambridge MA, United States \\ ${ }^{2}$ Department of Economics, Middle East Technical University, Ankara, Turkey \\ ${ }^{3}$ College of Administrative Sciences and Economics, Koç University, Rumeli Feneri Yolu, Sariyer, Istanbul, Turkey
}

*Corresponding authors: Ilhan Can Ozen, Takemi Program-Department of Global Health and Population, Harvard University, Cambridge MA, United States, E-mail: iozen@hsph.harvard.edu

Received: 16 Mar, 2021 | Accepted: 28 Apr, 2021 | Published: 10 May, 2021

Citation: Ozen IC, Tuncay B (2021) Predicting the Resilience of the Health Care System to New Arrivals: The Case of the Public Health System of Turkey. J Epidemiol Public Health Rev 6(2): dx.doi.org/10.16966/2471-8211.212

Copyright: (C) 2021 Ozen IC, et al. This is an open-access article distributed under the terms of the Creative Commons Attribution License, which permits unrestricted use, distribution, and reproduction in any medium, provided the original author and source are credited.

\begin{abstract}
Purpose/Objectives: Since the start of the Syrian war, a significant population has moved out of the Syrian Republic into its neighborhood environs. Turkey has had a significant effect on its health system and society, as a significant new number has entered the Turkish society, increasingly using the Turkish healthcare system. Our aim is not only to numerically identify the size of the effect to the Turkish system, but to identify the domestic resources that allow the Turkish healthcare system and society to build up resilience against the significant health demand shock. The main objectives of this study is 1) To understand whether there is a complementarity between the earlier efforts in the Turkish health system and the current capabilities that is necessary to meet the Syrian Populations Health Needs. 2) To understand if the newly revamped Turkish Primary Healthcare System Provide a crucial buffer for the negative congestion effects that could have been caused by such a significant and relatively unhealthy refugee population being integrated into the health system, at a relatively rapid pace.

Research method: The main two outcomes that the analysis plans to predict are the changing efficiency and the changing user satisfaction of the Turkish health system. Using multi-level regression models (MLO) we (i) Start by looking at the effect of the Syrian effect on the crucial Turkish health parameters, following this by (ii) Looking at the factors of family health program introduction, and family health system utilization to look at how the functionality of the health system, and the satisfaction that it brings to the Turkish population is being affected. We used fixed effect model to remove unobserved heterogeneity in each province (model specification in Appendix 1). We have controlled for health system variables (public primary physicians per 10,000; public hospital specialists per 10,000; public hospitals per 10,000; public PHC centres per 10,000; and the presence of a university hospital in the province) as well as population characteristics (rural population (\%); population aged 65 and over (\%); population aged 14 and under (\%); and the province population). Because demographic data was available only for the years 2007-12, it was linearly extrapolated for the years $2002-6$ and 13 . The penetration of family medicine model in each province was measured by an indicator variable $(0,1)$ for whether the MLO model was introduced, and the number of years since the introduction of the MLO model. The Syrian effect was measured through the proportion of Syrians under temporary protection status to the domestic province population.

Main results: The health system status of the Turkish population is unaffected in the large period from 2011-2016. The significant effect in the initial period was significantly alleviated in the intervening years. The main sources of resilience were found to be the changing importance of the alternative primary health system that allowed Turks to receive a new option to the secondary part of the Turkish health system that was increasingly congested. Increasing use of the immunization for the same goal is also substantiated for the Turkish population.

Recommendations: Turkey's experience is instructive for a lot of the middle income countries, which can face similar refugee and migrant pressure in the next 50 years. The health systems priority to UHC and to (relative) open access that it offered to its citizen population and its outside populations alike, has served its efficacy in good stead. The health system must create enough elasticity to limit a drop in health system satisfaction and health system utilization in either of these critical populations.
\end{abstract}

Keywords: Socioeconomic variables; Public health; Health economics; Health and economic development; Health and inequality

JEL Classification: H21, L92, R4, I12, 121, 131, J13 


\section{Introduction}

Turkey's health system is under significant pressure from the Syrian refugee influx. Because of the demography, and movement rationale for the majority of the Syrian population, the most important sector that has done the majority of the job has been the health sector, which has consistently played a big role in the integration process of the Syrians. These populations have significantly low level of health and have been vulnerable to adverse health shocks, even before their arrival.

In a general historical story of refugee shock [1], and refugee integration [2] that has defined the 2010s, Turkey has become a leading country as the top refugee recipient in the world. As well as this, in terms of refugee spending [3], and especially spending on health [4]. Turkey is taking a prominent position, among the countries in the region $[5,6]$ and on a global scale as recognized by UN institutional declarations.

The issue is how Turkey is receiving and integrating such an important new population into its health system. Although a lot of research has outlined the size of the challenges, the different contours of the Syrian health demand, the basic health characteristics emanating from the Syrian demography, the majority of the papers have zeroed in on the language problems that have characterized the health service given to the Syrians $[7,8]$. But in terms of numbers, what is more striking is the number of people who have been integrated to the health sector, as well as the pace at which the integration has taken place. This paper outlines which characteristics of the Turkish health system has allowed the demand to be met. These characteristics can then be prioritized for future health shocks, as Turkey's position in an increasingly vulnerable position of the world geography will stay constant. The paper contributes to the health system resilience literature, where the ability of different health systems to absorb health and humanitarian shocks is quantified, and modulated [9]. In terms of quantifying health resilience we introduce the change in the efficiency scores at different spatial levels, to understand how the system is performing in terms of core operations. However we plan to improve on what can be said about the health resilience index, by contributing on which earlier health interventions in the system can be increasing this index.

Fundamental research question that motivates this work is related to earlier efforts the state has undertaken (in the dimension of UHC) in the absence of the refugee shock, and how the treatment efficacy and treatment efficiency for the refugee population changes as a result of these earlier efforts. The main objectives of this paper are focusing both on the size of the challenge, and to look at the size and source of the resilience from the Turkish health system, and the novel utilization methodologies of the Turkish population.

The paper is organized as follows: 1) Short literature review on the size of the health shock in the Turkish healthcare literature, and universal health systems literature on resilience. 2) Understanding the size of the health shock, its geography and the resulting health expenditures during the Syrian integration. 3) The health improvements of the Syrian population plotted against the expenditures of the Turkish health system, with the rudimentary efficiency scores being calculated for every Turkish province. 4) Looking at the aggregate health outcomes in the effected regions, and analyzing how efficiency of the different regional systems has fared. 5) Calculating the independent effect of the family health reform on absorbing the shock of the Syrian influx, both in terms of the use of inputs, and in terms of the resulting outputs, and the resulting efficiencies of the Turkish healthcare system.

\section{Literature Review}

Based on recent literature, the literature defines health system resilience as "the capacity of health actors, institutions, and populations to prepare for and effectively respond to crises; maintain core functions when a crisis hits; and, informed by lessons learnt during the crisis, and re-organise if conditions require it." In light of this definition, health system scholars have tried to look at which countries performed well in situations caused by health shocks because of the appearance of a new disease (Ebola) [10], a social/civil unrest or severe economic crisis creating a delivery problem for the health system (South Africa [11]), natural disasters (Ireland [12]), in the presence of a general epidemic outbreak [13], and in the context of the recent COVID crisis [14]. Our analysis is under this grouping as it focuses on the context of new populations with potentially different forms of health need being introduced to the health system as a result of the unexpected refugee influx.

In this literature one of the most important goals is to produce estimates about the resilience of different health systems, understanding that this resilience must be measured in the presence of shocks that the health system is in the process of trying to overcome. To operationalize the concept [15], the following methods have been used, to look at the health systems under acute crisis, and look at crucial performative aspects, and evaluate them in terms of performance indicators [16].

This recognition prompted a view of resilience as involving the adaptation and transformation of systems [17] though the emergence of new structures such as policies, processes and organizational culture that enable organizations to continue to perform their functions in the face of challenges [18]. In health systems how the different units cooperate one another has to be seen as crucial in determining the resilience, as the resilient health institutions will have greater ability to transfer health demand from one of its arms to another, and to distribute the demand more equally between the different supply units.

Resilience in the case of Turkey's public health system has been under-researched, which itself is interesting. The case of the 1997 earthquake is discussed in the international public health literature as a case where the health system was not able to show the requisite resilient characteristics, but the latest case of the Syrian refugee crisis has been under-discussed in relation to resilience. This situation itself is unexpected, as the integration of 3.3 million patients to a modern health system is an unprecedented increase in demand, and how a modern health system shows such resilience will be crucial not only for the Turkish public health literature, but also the global public health literature.

\section{The Integration of the Syrians into the Turkish Healthcare System}

The population's arrival can be graphed in the following way, and the population's demography that has arrived can be summarized in this way, by this pyramid.

As the figure 1 shows there is a very large group arriving, with big spikes in arrivals in 2014, and 2015. Concurrently, with this process a large proportion starting with 2014 left the camp areas for the urban and peri-urban areas, where according to the latest numbers $93 \%$ of the Syrians currently reside (Table 1). Both the increasing numbers and the movement outside of the camps have made the need for the integration of the Syrians into the education, health and economic sphere increasingly acute.

Surveys conducted on the Syrians and Turks, has formally shown that health integration is the least contentious issue, with Syrians 


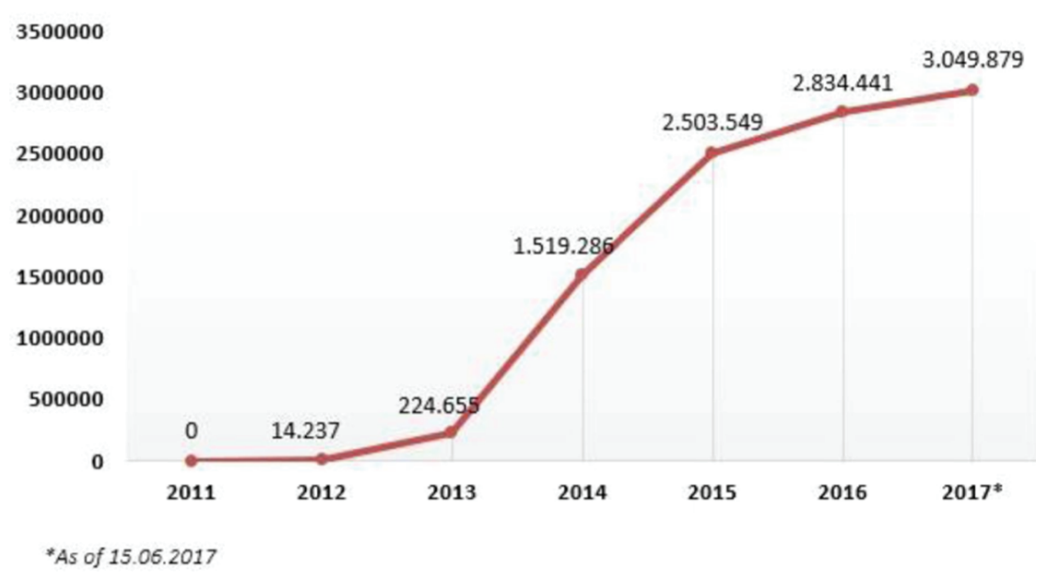

Figure 1: Time series: increase in Syrian refugees-Number of Syrians under temporary protection per year.

Table 1: Syrian patients and Turkish patient's application profile compared (geographic nature).

\begin{tabular}{|l|c|c|c|c|c|}
\hline All obs & GE (-1) & GE (0) & GE (1) & GE (2) & S.Gini \\
\hline & 0.008 & 0.007 & 0.007 & 0.007 & 0.061 \\
\hline \multicolumn{7}{|c|}{ Syrian patient geographic concentration } \\
\hline \multicolumn{7}{|c|}{24.497} & 2.132 & 1.645 & 3.986 & 0.836 \\
\hline
\end{tabular}

Generalized Entropy indices GE (a), where a=Captures the spatial sensitivity parameter, and coefficient of spatial distribution

announcing the biggest satisfaction from, and Turks announcing the biggest approval for the health integration of these new populations [19]. As a result a huge amount of expenditure has been spent on providing more than 26 million health interventions to the Syrian refugee population that have been afforded temporary protection status, in the crucial time period from 2011 to 2016 [20]. This is the biggest single health push for a refugee population brought out for a vulnerable population, and in this period for the entire world.

Although knowledge about the Syrian health effect is increasingly being discussed and its absolute size recognized in the international literature, little formal analysis has been carried out to understand how the new Turkish health systems already existing development path has allowed for the orderly integration of the refugee group in the second decade of the $21^{\text {st }}$ Century. During the civil war, which started in the final months of 2011, Syrian refugees arrived Turkey in great need of healthcare as a result of injuries, inferior living conditions and lack of access to healthcare services in their home country. Turkey hosts more than 3.3 million Syrian refugees as of 2017. Free healthcare is provided to Syrian immigrants in Turkey; registered Syrians can access primary, secondary and tertiary health services in their provinces of registration. Healthcare services offered to Syrians by the general health insurance are not different than the services provided to Turkish citizens. Patients have to pay a small amount of contribution fee at each visit using the general health insurance and Disaster and Emergency Management Presidency pays the contribution fee for Syrians. Free healthcare provided to Syrian immigrants in Turkey results in capacity problems in the provinces with higher immigrant-native ratio. Public hospitals provided more than 1 million inpatient care and 25 million outpatient care to Syrian refugees between 2011 and 2016 (Disaster and Emergency Management Presidency, 2017).
WHO reports that in 2013, two years after the start of the Syrian Civil War, at least 35\% of country's public hospitals are out of service and $70 \%$ of health workforce has left the country in some provinces. WHO (2013) also reports that many internally displaced people live in unsanitary conditions and without safe drinking water-which increases the risk of epidemic diseases. The Director of the Department for Communicable Diseases at WHO's Regional Office for the Eastern Mediterranean, "we are anticipating a number of public health risks from water-borne diseases, specifically hepatitis, typhoid, cholera and dysentery." In fact, increases in cases of acute watery diarrhoea, hepatitis A, typhoid are reported. Increased cases of cutaneous leishmaniasis (a disease transmitted to humans through sand fly bites) have also been reported. In addition, vaccine-preventable diseases such as measles have also reappeared in Syria. Polio outbreak was reported after 15 years of polio-free period [21]. WHO (2013) warns about an increased risk of disease epidemics in Syria and in neighboring countries. WHO reports that measles, tuberculosis, and cutaneous leishmaniasis have been reported among displaced Syrians in Jordan, Lebanon, Iraq and Turkey.

What we would like to know, but have had an incomplete picture up to now be the evolution of the performance indicators at the total system level, rather than specific steps of the system [22]. What we want to learn is the evolution and reaction of the new health system in the face of the influx of a significant number of Syrian Refugees in a specific period. We will analyze dataset from $10,444,290$ patient admission records, coming from the Syrian Refugees registered to the Turkish healthcare system between 2012 and 2014, together with utilization \& health satisfaction patterns of the Turkish patients coming from TDHS (2008-2016), and DHS 20132018 surveys summarizing the Syrian health outcomes, at the current period of integration.

We aim to show that Syrian migrants' health outcomes improved, with an orderly process of integration. Health outcomes are measured for the Syrian population with system wide improvement achievements, and efficiencies that are calculated for every province. The analysis of the evolving efficiencies is conducted with a discontinuous time series design, where the patterns of improvements/damages are analyzed through time, at the province level. The Syrian effected provinces will be analyzed in detail, in terms of their starting efficiencies, and how their efficiency pattern progressed in the intervening periods. 
Resilience here will be identified as a regional extra increase in efficiency in the shocked provinces.

In the second part of the research we focus on the Turkish health outcome parameters to show how the domestic population has fared. The shocked provinces are again grouped together, and group means are differentiated from the national mean with a $\chi^{2}$ distribution. At the final analysis, the factors of resilience are investigated, with the shocked provinces differentiating health demand characteristics, and the effect on efficiency of these characteristics are jointly investigated.

The focus will be on the contextual factors of refugee integration into a provincial health system, with a multi-level regression analysis used to capture the size of the effects. The focus of our interpretation of the results will be 'structural' in other words the fundamental characteristics of the Turkish health system, in terms of its rewarding schemes, and its differentiation between the first and secondary stages, Specific importance will be given to the integration paths of the Syrians, who were given cost free access to the secondary public level of the Turkish healthcare system, and the primary healthcare system only later. The resilience that the Turkish health system and the primary healthcare utilization change of the Turkish population allowed this orderly, and relatively low indirect cost of integration to take place.

\section{Data Inputs}

The main dataset comes from the Medulla System that keeps the collected records from Ministry of Health $(\mathrm{MoH})$ affiliated hospitals and primary health clinics for every locality (anonymized) for all the health applications that have occurred during a given year. The data provides detailed information on the hospital characteristics, treatment type, initial diagnosis, and prescription and treatment for all the identified applications from the Syrian population, as well as information on the residency, gender and age dimensions of the anonymized Syrian patient population.

The effects of military conflicts on health are mostly documented with a survey data and our study is expected to make a significant contribution to the literature using a distinctive registered administrative panel dataset. Dataset used in this study is not a survey data and aims to contribute to the literature by its uniqueness. Our panel dataset is very unique gathering micro level health information of the Syrian patients from hospital and primary health clinics administrative records. Moreover, the study examines the effects of a massive refugee flow on Turkish healthcare system for the most critical time periods between 2012 and 2014.

Our main data on Syrian Populations healthcare system utilization comes from the MOH's central information database.

These data are routinely collected by all primary, secondary and tertiary healthcare providers in provincial administration units and transferred electronically each month to the MoH's central database (Health-Net information network).

Our data on the demographic characteristics of the Syrian Population comes from the demographic work done by the Hacettepe Institute of Population Studies, and the Ministry of the Interior, Migration Department.

Our data on the prices of the services, prescriptions and operations that were performed on the Syrian population comes from the SUT database, which gives the price levels announced by the $\mathrm{MOH}$ for the different operations on the health system. Price of pharmaceutical products comes from İTS (İlaçTakipSistemi) database, which carries updated information on publicly available pharmaceutical products and their corresponding prices. Price per patient of hospital level fixed costs for inpatient admissions comes from the SUT price index.

Data pertaining to hospital resources of the Turkish healthcare comes from Health Statistics Yearbooks issued every year by the $\mathrm{MOH}$ and the Hospital Almanac issued by the Public Hospitals Directorate affiliated with the $\mathrm{MOH}$.

\section{Data Analysis and Results}

This part will be organized as follows: first we will look at the characteristic of the shock variable (the integration speed and geography of the Syrian refugees) and discuss why it is a shock variable that can be used and differentiated to identify its effect in a multi-level regression framework. So the first two parts of the data analysis will understand the size of the shock and the geography of the shock. The next two parts will conceptualize the expenditures that the Turkish health system has spent, in order to integrate the Syrian population, and the resulting level of health improvements and efficiencies. The final data analysis part will analyze the micro sources of resilience that significantly improve efficiency, and the limitations that hamper resilience, at the provincial level. The regression framework and the significant variables of interest will be introduced.

\section{Numbers of arrivals}

In terms of the numbers of Syrians who have showed up, figure 1 suggests that the majority of arrivals have happened after 2014, with another important increase in the year 2015. The geography of the arrivals suggest that the provinces on the Syrian border, and adjacent to the border are under increased stress, with more than 90 percent of the Syrian arrivals residing in these areas at the time period of our analysis, which spans from 2012 to the end of 2014.

As such an important part of the refugee group has integrated into the Turkish society, the number wise increase in the Turkish healthcare system is quite significant. Although in terms of the overall size of the health sector, the new arrivals do not seem significant, the extreme clustered nature of the demand shock is clear when you look at the Syrian patient profile, with respect to the Turkish application profile (Table 1). Especially when we look at where in the Turkish health sector the Syrians have been integrated, it is clear that the refugee population has been integrated in the part of the health sector that is still under-provisioned (The correlation coefficient between the point of contact of the Syrians with the health system and the health system development score of these regions is-0.27). Another point that needs to be made is that the needs of the refugee population from the health system will be acute, as the drop-off in the health-values of the refugee population in the years before they cross the border has been pretty significant [23]. This situation makes us think that issues that have to do with overutilization of resources and quality limitations of the healthcare services should be prioritized in our discussion (Figure 2).

\section{Turkish patient general geographic concentration}

In terms of timing of the arrival, and the systemic absorption of the Syrian population in the Turkish healthcare system, the numbers have grown significantly year after year, with the new significant numbers joining every month, mostly to the 10 province health system.

The first issue that we will exploit in the data analysis is the extreme localness of the shock coming from Syrian refugees. This can be seen easily in figure 3, which quantifies the potential impact of the Syrian arrivals on the local health system comprising of at least 10 percent Syrian refugees (known as the 10 provinces in the south and southeast 


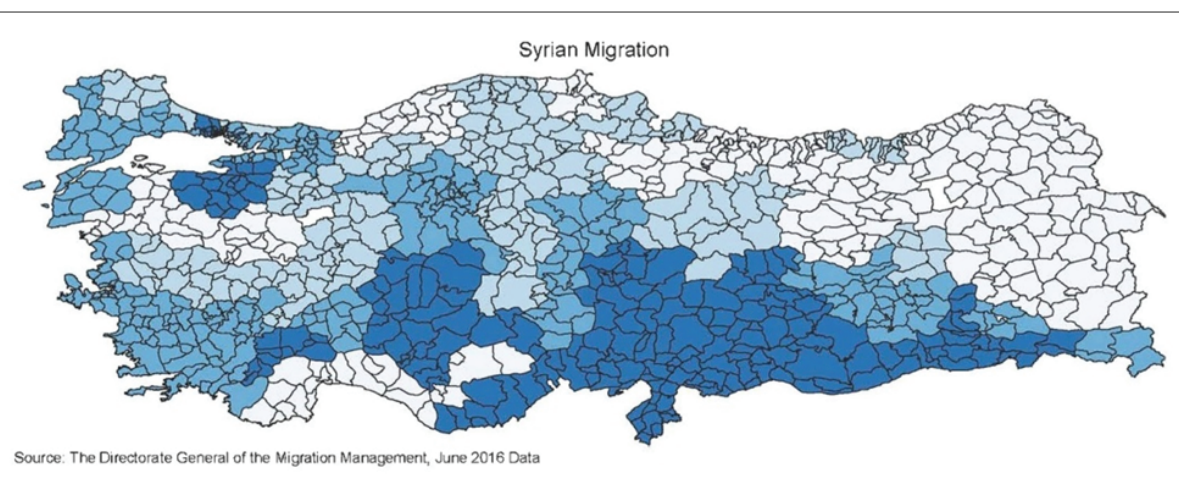

Figure 2: Map of new arrivals.

quadrant of Turkey) and all other provinces, in terms of how much the regular health demand increases by compared to the pre-2012 average. As the arrivals to Turkey were highly spatially clustered in the 2012-2014 period, and as the health laws to the Syrian refugees have stipulated that Syrians first apply for their health demands in the provinces they were registered, the health demand of the Syrians are very spatially clustered as well. What this means is that a special, and spatially clustered part of the Turkish health system has to meet the extra demand coming from Syrian refugees. This is the crucial shock variable component that we will utilize in the regression framework. As the shock is quite geographically located, it will allow us to differentiate, in a multi-level regression framework between the provinces that were affected, and those that were not.

The shock that affects the Turkish health level, and after the system shows resilience determines the Syrians health level, is modelled as the arrival of the Syrians. We conceptualize not the actual location of the Syrians, but where in the Turkish health system they demand their health as the crucial shock variable. In the robustness check we also look at the residence characteristic of the Syrian populations, and see if our results change. The overall results stay broadly the same.

Timing data: What has been the evolution of application figures throughout the years? Is there an overall story of further integration?

In terms of the timing of applications, the overall application numbers have increased significantly from 2012 to 2013 and from 2013 to 2014. In terms of the new applicants every month, the number reaches close to 180000 new patients every month, which is a significant number for any health system to integrate (Figure 4).

\section{The level of expenditures related to the Syrian health integration}

The level of expenditures that the Syrian population's integration is creating is completely covered at the healthcare dimension by the Turkish government, so the issue of out-of-pocket disaggregation is non-existent in this case. However in terms of cost sustainability, it is important to look at the level of costs, the disaggregation of costs among different medical functionalities, and the level of costs that are created in the different localities. In terms of how we have created the total expenditure, we have used a composite price index, collected from three different data sources to create current price index for the treatment that was received by the Syrian population, the hospital costs as a result of the hospital stays of the Syrian population, and the pharmaceutical expenditures as a result of doctor prescriptions, fully covered by the Turkish budgetary sources. We have created two sets of expenditure calculations, one based on reference year prices for the 2012-2014 periods, and another current expenditure calculation done under 2019 prices for the same services.

After we construct the three price indices, for the gross expenditure calculations of the Syrian calculation, we use the formula:

$$
\sum E_{i}=\sum P i j \times X i+P i k \times K i+P i p \times R i
$$

Where $\mathrm{Xi}, \mathrm{Ki}$ and $\mathrm{Ri}$ are the treatments, hospital stays and pharmaceutical products that are offered to the Syrian population. The summation that is undertaken sums the health expenditure that is done for all Syrian patients that have applied to the Turkish health system.

When we follow this overall calculation, the total amount of expenditure is equal to 1.575 billion $\$$ for the entire period between 2012 and 2014, which is a sizeable investment, and represents the most significant single country health overlay for the health needs of the Syrian refugee population. These calculations are undertaken under 2012-2014 prices, and the 2012-2014 exchange rate between TL and \$. We see that the expenditure quadruple from 2012 to 2013, and doubles from 2013 to 2014 (Consult table 2). We look next to the by sources distribution of this health expenditure.

The consistent position of pharmaceutical costs, encompassing 10 percent of overall expenditures, and reaching the level of 150 million \$ by 2014 (in 2014 prices) allows us to remark that a significant amount of pharmaceutical cost per patient seems to be incurred for the Syrian population (120 \$ for every Syrian covered) as well as signaling a significant amount of access that the Syrian refugee population is able to get to modern medicine, via the Turkish healthcare system.

Aggregate health outputs, high quality access and efficiency levels (2012-2014) post-shock resilience of health system

The existing research mostly in Jordan $[24,25]$ and Lebanon $[25,26]$ suggests that the effect of the Syrian Civil War on the macro health outcomes of these populations that have been fleeing has indeed been sizeable [27]. The health problems and the health vulnerabilities of the Syrian Refugee Population is indeed significant [28], and investigating the multidimensional access difficulties $[29,30]$ of this population, and the vulnerable subpopulations [31] is critical. The same research also indicates that a sustainable public health policy [32,33] should keep the health outcomes of the domestic populations unchanged, while improving the outcomes of Syrian refugees. All these findings of established literature have decided our categories of analysis, and our research priorities for this paper. 


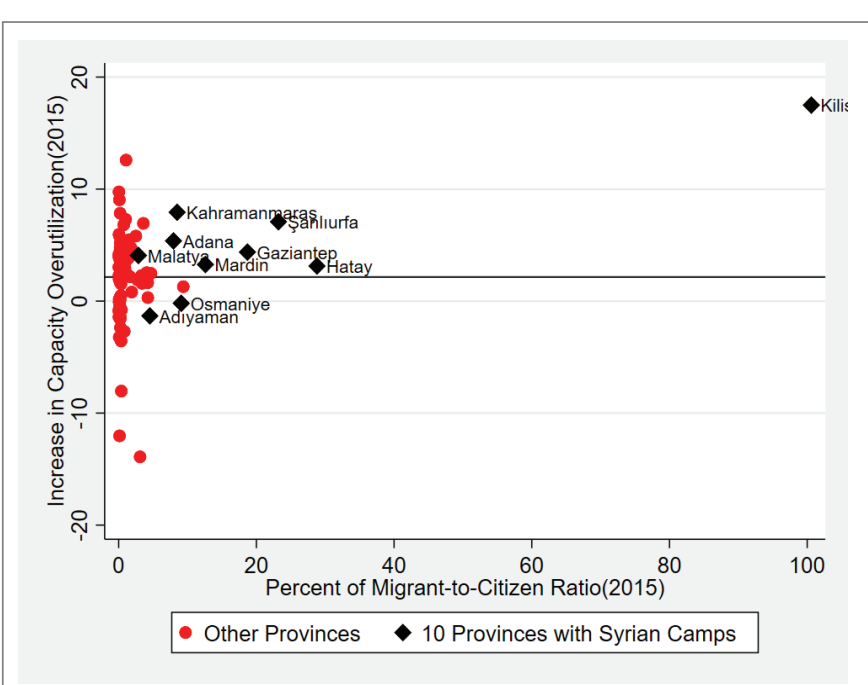

Figure 3: Potential excess demand on health capacity as a result of the Syrian influx (2012-2014)

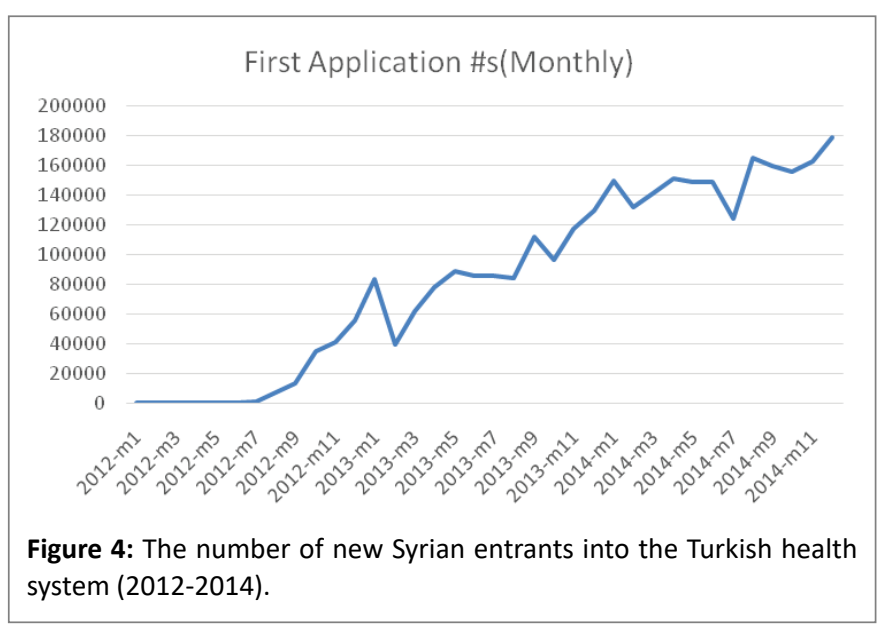

Table 2: Total expenditures by year.

\begin{tabular}{|l|c|}
\hline \multicolumn{1}{|c|}{ Year } & Total expenditure-Syrian health (2014 Prices) \\
\hline 2012 & 198946197.15 \\
\hline 2013 & 783692016.80 \\
\hline 2014 & 2186614903.85 \\
\hline
\end{tabular}

As a first investigation, in order to look at the shock effect, descriptively we look at the Turkish-DHS data, to capture the effect on the aggregate health output dimension (for the Turkish domestic population) in two of the most typically quoted dimensions of life expectancy and under 5-mortality. The results, summarized in figures 5 and 6 , represent the case that there was an initial slowdown in aggregate health outputs in the effected provinces at the start (20112014), but the outputs were then able to catch up to national averages in the later integration period (2015 and more pronouncedly 2016). This is fully in line with a picture that the health system is doing better as time goes by with the initial shock, with an accumulated ability to deal with the size of the health shock, becoming clearer by 2016 .

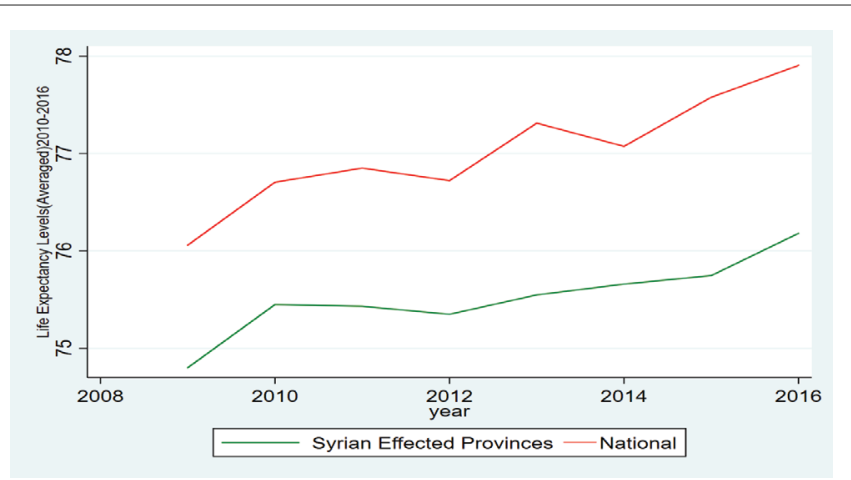

Figure 5: Life expectancy of effected and non-effected provinces compared (Turkish DHS data).

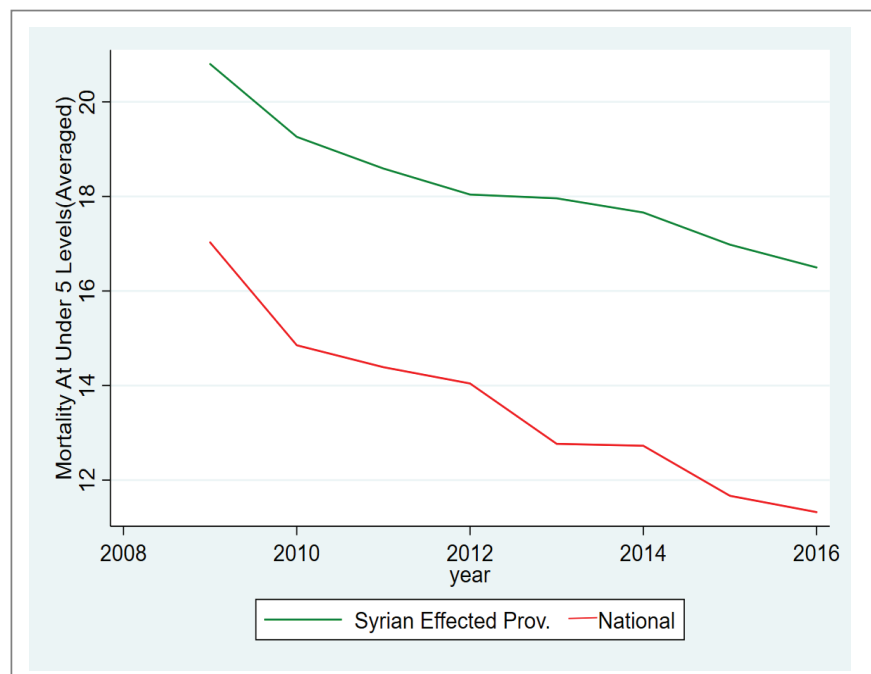

Figure 6: Under-5 mortality of effected and non-effected provinces compared (Turkish DHS data).

This general result is supported when we look at the macro levels of improvement and health system reaction more closely. On the sustainable output dimension, the second dimension we will focus on is the number of healthy discharges that the Turkish health system reports for every period. The main data on Syrian health applications to the Turkish health system also records the times, and characteristics of the Syrian population that has been healthily discharged. We use this information to evaluate the health output of the overall system, and the specific health units that are providing health to the Syrian population.

When we look at the development of these series through time, what we observe is that in terms of health improvements (Figure 7), there has been a marked improvement year after year in the ability of the health system to achieve improvements for the Syrian population going from 2012 to 2014, with a marked jump observed moving from 2013 to 2014.

When discussing the appropriateness of the healthcare, and the needs-capabilities match of the health system, we will first look at the quality of hospital that the Syrians are applying to. In the analysis of Syrian integration in the different host countries, serious problems of 


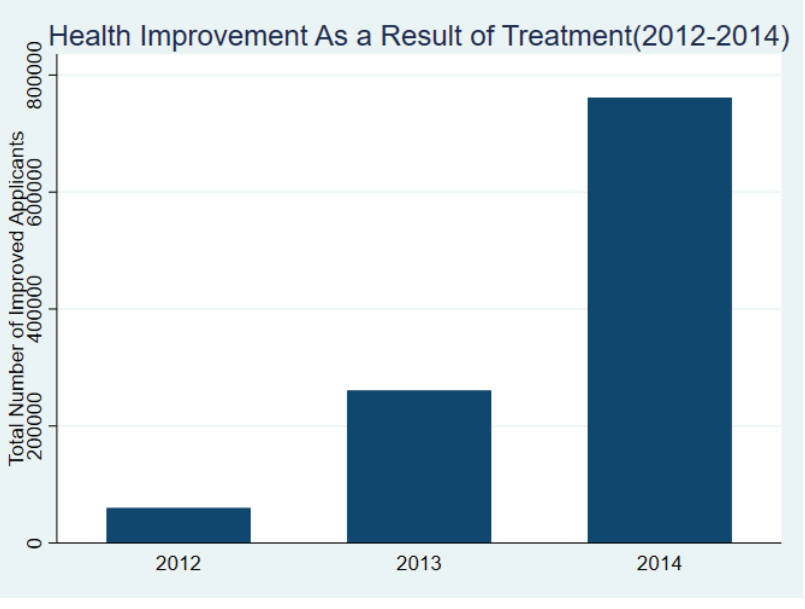

Figure 7: Changing health improvement levels (aggregate) in the treatment of Syrians (yearly).

access [34] to high quality and timely care have been uncovered by researchers [35], in many different levels including the tertiary level [36].

Looking at the Health ministry records, the public hospitals are ranked according to their capability and resources by the Public Hospitals Directorship. The first thing we do is compute the average capability and resource of the Turkish hospital that Syrians are reaching, and differentiate it by the year. The results are summarized in table 3.

The picture we see is, with the level of health institutions that the Syrians are able to reach being upgraded consistently, year after year from 2012 to 2014 (Table 3). This suggests that the health services that are provided to the Syrian population are being provided by a higher capability and higher resource level.

The final health dimension of efficiency captures to what extent the quality healthcare is provided to the Syrian population at the lowest possible expenditure level, at the individual level and at the systemic level. Specifically, we have estimated the initial efficiency scale as a combination of the health improvement grade that we have already calculated, and the health expenditure dimension that we have already calculated. Specifically our efficiency measure, aggregated at different levels of spatial focus is equal to

$$
\sum I i / \sum E i
$$

When we look at the efficiency scores of reaching these improvements, calculating how costly it has been to achieve these aggregate improvements (aggregated to the Syrian population), it shows a marked consistency of efficiency scores, with the highest consistent yearly averages achieved in 2014 (Figure 6), suggesting how the Syrians were treated, and how the health system for refugees produced health outputs became standardized after 2014. This is an important cutoff date, since the majority of Syrians started being processed by the health system after 2014, with a more streamlined access given to Syrians, with unconstrained access being given to the Syrians (except being constrained by the location of their residence). The increased and consistent efficiency scores is a good sign for the further integration of the Syrians that were planned to be achieved in the 2015-2016 period.
When we look at the provincial breakdown of the improvement, and the efficiency scores, what we see is that in 2012 there is significant difference in overall efficiency to the healthcare services that are provided to the Syrian population. Just as expected, the low capability, low resource part of the national health system identified in figure 8 , is also the area where the biggest health efficiency problems seem to reside. However, the positive feature is that as we move from 2012 to 2014, the health efficiency scores in the provincial scores decrease in variation, and increased improvements over the national average are seen in the places that are seeing increased Syrian influx. The two exceptions to this rule are the two provinces of Kilis and Osmaniye (Figure 9) which are still lagging behind in terms of health efficiency and health efficiency improvements.

The spatiotemporal pattern of efficiency suggests that the greatest increases in efficiency gains have occurred in the geographies which are housing and servicing the greatest amount of refugees (there are two exceptions). This is a good evidence of building resilience in the healthcare system. In terms of future sustainability, and future improvement opportunities, and further integration abilities of the system, these resilience characteristics that have been built up between 2012 and 2014 will be invaluable.

In the secondary part of the data analysis, we will show what characteristics of the health system allowed the system to create higher outputs without creating extra costs, extra inefficiencies, or extra negative health externalities for the Turkish domestic population, which will be shown in the next part.

The basic mechanism that balances the extra health burden arising out of the Syrian refugee influx is the universal primary healthcare system, which was introduced into the overall Turkish geography prior to the arrival of the Syrians in 2012. Although the geography that is effected significantly by the Syrian population movement

Table 3: Hospital quality level (average) for Syrian patients.

\begin{tabular}{|l|c|}
\hline \multicolumn{1}{|c|}{ Year } & Average Hospital Level for Syrians \\
\hline 2012 & 5.609 \\
\hline 2013 & 5.892 \\
\hline 2014 & 6.071 \\
\hline
\end{tabular}

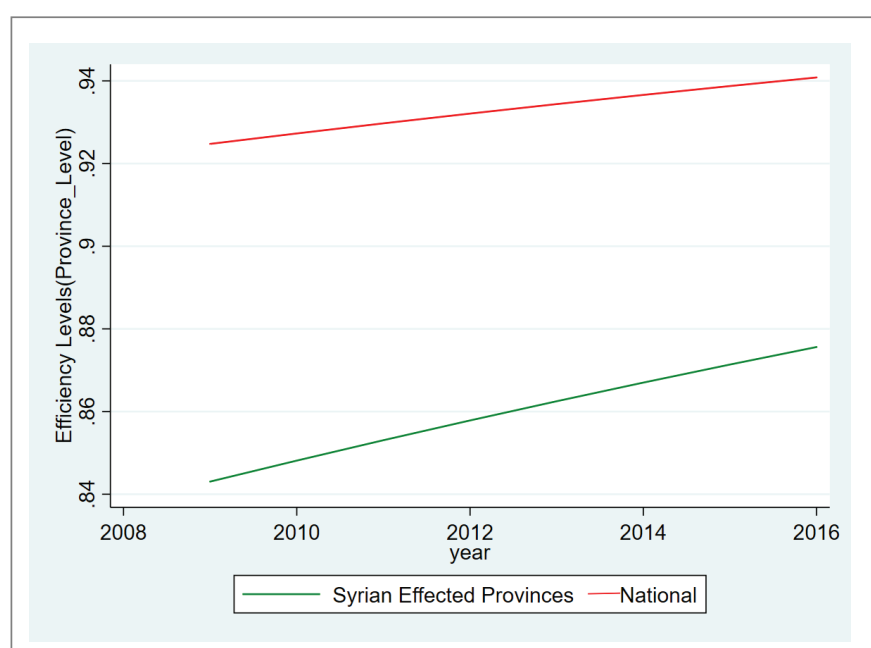

Figure 8: Efficiency level of effected and non-effected provinces compared (authors calculations from E-Nabiz data). 


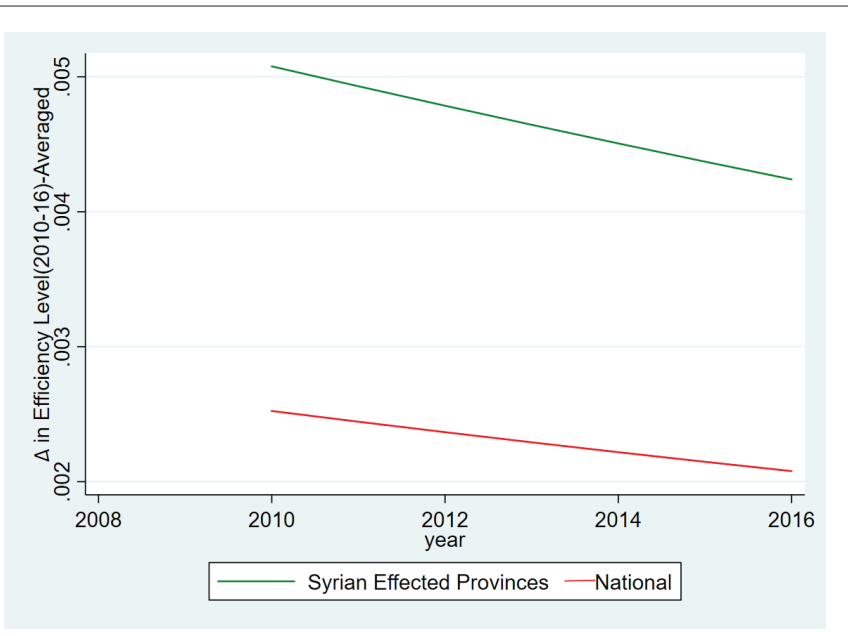

Figure 9: Efficiency changes in effected and non-effected provinces compared (author's calculations from E-Nabiz data). introduced primary healthcare system relatively late (at 2010), still the mechanism was available for the Turkish population to substitute away from secondary healthcare services, which were under the increased pressure of Syrian applications, and towards the primary healthcare services which are much more targeted, individualized, lower cost, and crucially separated according to the Turkish population, and the Syrian population (which received their own primary healthcare system starting 2016).

What we will introduce is the implementation year and implementation intensity of the family healthcare reform to the different provinces, and look at the effect of this. We will investigate both the effect of primary healthcare reform on the health service that the Syrians are receiving, and the health service utilization and health quality that is afforded.

The efficiency and efficiency change effects we document in figure 8 and 9 , is in line with the two observations that are also in line with the initial aggregate health outcomes. The areas which were affected by the health shock had low health values, and low health efficiencies (Figure 8), and so represented an increase in vulnerability in already vulnerable geographies. However, the point we will investigate further can be observed in figure 9, such that the regions under this important vulnerability have actually had significant increases in efficiency. What we will investigating with regressions, is what will be the channels and determinants of this gaining of efficiency at the province and individual level.

Figure 10 represents an interesting regularity that we will utilize in our analysis. The Syrian integration has happened in a very unequal way between the primary and secondary stages of the health system, with the integration path that occurred being very secondary-stage biased [37,38]. Although many reasons exist for this, especially with respect to institutional rules [38], and there has been a recent trend that plans to reverse this, this paper will take this fact as given, and as a starting point for the analysis of health variables and behaviors between 2010 and 2016. With the introduction of this unequal shock, the (provincial) health system that adapts better, will be a system that converts its secondary health system applications to primary health system applications at a faster clip in the analysis period (2010 to 2016). In the absence of this social resilience $[39,40]$, and efficiency increasing

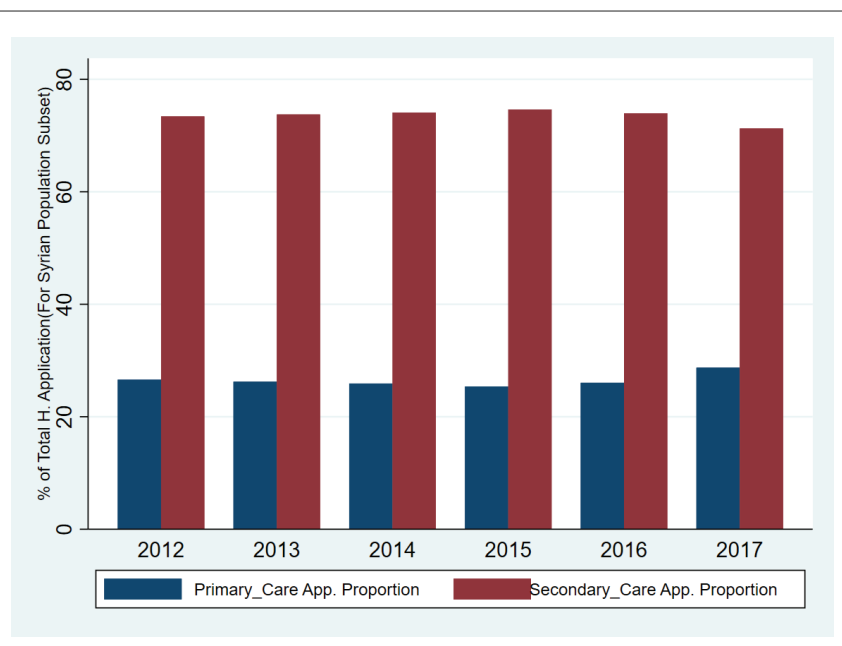

Figure 10: The Syrian health profile distributed among the primary and secondary stages.

mechanism, the efficiency will be harmed and the congestion effects will be created, that we will track through the change in the emergency room applications in the same analysis period.

Figures 11 and 12 clearly show the differentiated effects in the provinces were Syrians have increasingly integrated into the Turkish health system, compared to all the other regions. The regions are in the top $20 \%$ of the primary healthcare adapters from 2010 to 2016 , with one of them consistently occupying the leading position. This analysis is done both in terms of the provinces rate of primary healthcare pickup, and the intensity of the primary healthcare use (Figure 11), in terms of the number of visits (Figure 12) to the primary healthcare doctor per year. Both these effects together suggest that a significant movement has happened in the direction of using more family health doctors, in a more intensive fashion. In the next stage of the analysis we want to look at what are the determinants of family health doctor pickup, as family health doctor use is a crucial determinant of the Turkish health system geography in the post 2010 period (Tables 4-6). Our regression setup captures the crucial variables that predict high family health doctor use, and integration. As the exact converse of this observation, the absence of family health doctor use would be expected to lead to higher emergency room applications, through a decreased efficiency of the health system use. Our hypothesis will be that, controlling for primary healthcare pickup characteristics, geographies with large health shock that occurred as a result of the Syrian integration will see a greater increase in emergency room applications.

In the regression setup, the control variables that we use, except the Syrian shock variable that is the main focus of our paper is pretty standard. The structure specifies the (i) Supply-side variables ${ }^{1}$, (ii) Demographics ${ }^{2}$, (iii) Socio-economic development ${ }^{3}$ and (iv) Underlying yearly trends that influence the take-up rate of starting to use primary healthcare doctors ${ }^{4}$. Although table 3 and table 4 supports the hypothesis that once it is taken up, the primary heathcare use increases the satisfaction that the domestic population derives from the health system, the takeup of this part of the health system is quite geographically uneven. The introduction time of the family healthcare system in a province for one, seems to be significantly affecting the takeup rate. As the majority of the variables are at the individual level (health surveys from 2010 to 2016) and the hospital level (efficiency calculations) the framework will be a multi-level framework, where the 


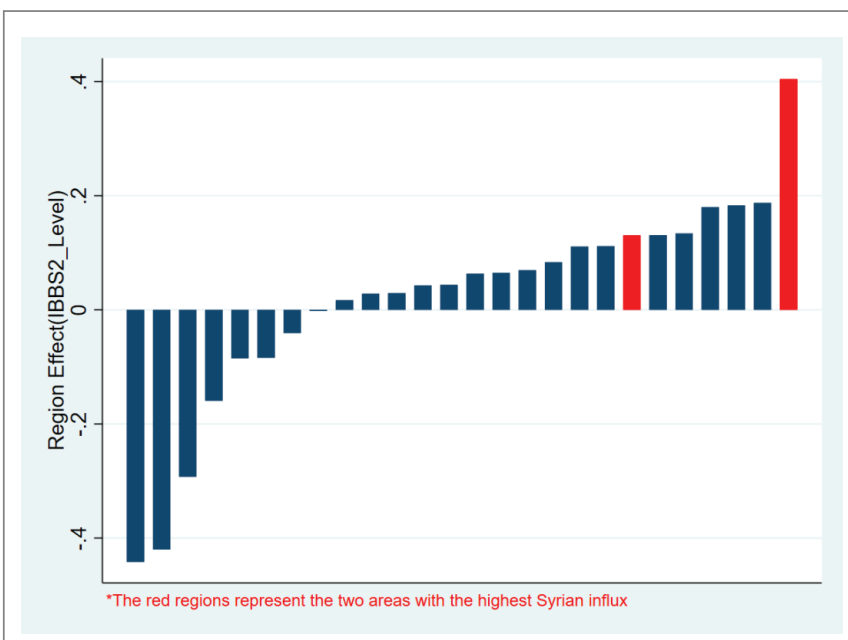

Figure 11: Change in probability of using $\mathrm{FMH}^{1}$ by families (differentiated by region)-2010 to 2016.

${ }^{1} \mathrm{FMH}=$ Family Health Doctor that is assigned to every family after 2010, in order to reach the targets of increased efficiency and health responsiveness in the primary stage [40].

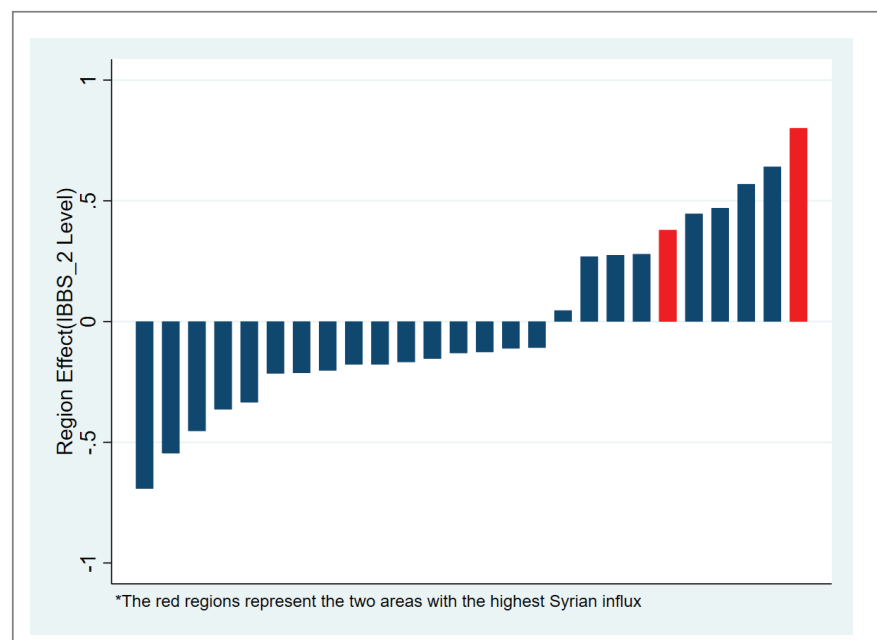

Figure 12: Change in number of $\mathrm{FMH}^{2}$ visits by families (differentiated by region)-2010 to 2016.

${ }^{2} \mathrm{FMH}=$ Family Health Doctor that is assigned to every family after 2010 .

Syrian shock effect will be creating a contextual effect in the province level, that we will investigate with figure 11 and figure 12 , and with the regression supplementary tables 7-11.

The results listed in tables suggest that the expectations we have both about the primary health take-up, and the emergency room applications is right. Using different specifications, primary healthcare utilization is increasing significantly in the areas with Syrian health shock (Table 7), suggesting that the primary healthcare system compensates for the increased congestion in the secondary healthcare system, provided the trust for the primary health system has reached a crucial level, with increasing time span of this system (Table 7) and the average utility Turkish citizens announce when they use it (Table 8). When we look at the full set of explanatory variables (relating to health demand and supply), we find that in addition to this, the poverty levels
Table 4: OLS for the Turkish patient's health satisfaction.

\begin{tabular}{|l|c|c|}
\hline \multicolumn{1}{|c|}{} & B & s.e. $(\boldsymbol{\beta})^{\mathbf{3}}$ \\
\hline Health development & 0.1656 & 0.0576 \\
\hline Health investment in $2^{\text {nd }}$ health level & 0.13 & 0.07 \\
\hline Primary healthcare introduction & $0.451^{* * * 4}$ & .154 \\
\hline Income-provincial GDP & 0.133 & 0.01 \\
\hline Age distribution & 0.253 & 0.134 \\
\hline
\end{tabular}

${ }^{3}$ Denotes the standard error of the coefficient

${ }^{4}$ Significant at the 0.025 alpha level

Table 5: OLS for Turkish patient's health system utilization.

\begin{tabular}{|l|c|c|}
\hline & B & s.e. $(\boldsymbol{\beta})^{10}$ \\
\hline Health development & 0.33365 & 0.081 \\
\hline Health investment in $2^{\text {nd }}$ health level & 0.346 & 0.101 \\
\hline Primary healthcare introduction & $1.04^{* * * 11}$ & 0.409 \\
\hline Income-provincial GDP & 0.157 & 0.708 \\
\hline Age distribution & 0.267 & 0.181 \\
\hline & $\mathbf{B}$ & s.e.( $\boldsymbol{\beta})^{12}$ \\
\hline Health development & 0.01 & 0.003 \\
\hline Health investment in 2 ${ }^{\text {nd }}$ health level & -0.22 & 0.15 \\
\hline Primary healthcare introduction & $0.83^{* * * 13}$ & 0.33 \\
\hline Income-provincial GDP & 0.036 & 0.005 \\
\hline Age distribution & 0.0303 & 0.0109 \\
\hline
\end{tabular}

${ }^{10}$ Denotes the standard error of the coefficient

${ }^{11}$ Significant at the 0.025 alpha level

${ }^{12}$ Denotes the standard error of the coefficient

${ }^{13}$ Significant at the 0.025 alpha level

Table 6: OLS for Turkish health systems-changing efficiency levels.

\begin{tabular}{|l|c|c|}
\hline & B & s.e. $(\boldsymbol{\beta})^{14}$ \\
\hline Health development & 0.1192 & 0.021 \\
\hline Health investment in $2^{\text {nd }}$ health level & 0.0131 & 0.0192 \\
\hline Primary healthcare introduction & $0.172^{* * * 15}$ & 0.028 \\
\hline Income-provincial GDP & 0.0177 & 0.005 \\
\hline Age distribution & 0.098 & 0.119 \\
\hline
\end{tabular}

${ }^{14}$ Denotes the standard error of the coefficient

${ }^{15}$ Significant at the 0.025 alpha levels

in provinces is another factor ${ }^{5}$ limiting the primary healthcare system take-up, which damages the resilience of the system (Table 9).

${ }^{1}$ We use the first two principal components of a set of correlated variables, capturing the number of health professionals and healthcare facilities and utilization (the number of consultations) for the years 2010-16 at the province level [41].

${ }^{2}$ We focused on the gender ratio and the old age ratio that are the two demographic characteristics that could be related to primary healthcare utilization.

${ }^{3}$ Average poverty rate, and the local GDP per capita (provincial) is the main socioeconomic determinants that we will focus on.

${ }^{4}$ The changing satisfaction from the primary healthcare system utilization is used here, to predict the evolution of the primary healthcare 
pickup, with the hypothesized relation being that higher satisfaction in the earlier periods predicting future pickup [42].

${ }^{5}$ This is a result that we want to investigate further in future papers, relating the social determinants that strengthen or weaken channels of health resilience [43].

Conversely, in areas where limitations in the utility, availability and attraction of the primary healthcare system exist, the health shock of the Syrians increasingly get converted to emergency room applications, which create efficiency problems, as it takes away from appropriate health care. This is corroborated with respect to the health system-health supply controls (Table 10), and also with respect to other demand and primary healthcare characteristics (which is negatively associated with emergency room applications) that are outlined in table 11.

In table 12, we provide evidence for the increased vaccine coverage of the Turkish population as a result of the Syrian refugee effect. Although it is preliminary, in the case of Hepatitis B, there is a both a negative effect of the Syrian effected provinces in changing the incompleteness of child vaccine outcomes (so that they are fully vaccinated) and also a compounded negative effect in the provinces where the family health program is better established (which we instrument with the amount of years since primary healthcare reform has been instituted in the province) to be even more likely to complete their vaccine series. Both these effects suggest that domestic populations provide extra vaccination coverage to pre-empt any extra visitations with their children to the emergency care rooms, and the congested secondary care units. It needs to be noted that our preliminary results on vaccination take-up and completion is in line with our results of family healthcare pick-up and utilization.

The crucial point of the analysis is to control the resources that Turkey has accumulated both before the Syrian Arrival (pre-2012), and as a result of the health shock, to buffer the operations of the system (between 2012 and 2016). To these resources, our data also adds the primary care reform implementation periods, which created an independent path for Turkish citizens to enroll in, which is independent of the secondary applications in the health system they are already making. After 2012 we differentiate between the primary health system's intensity (doctor per patient ratio) as it is not very expenditure and technology-oriented, and in the secondary and tertiary level we focus on the level of provincial health expenditures.

The results substantiate the outstanding importance of the primary healthcare reform, not only for the health conditions, and natal health outcomes of the Turkish population, but for creating the crucial health resilience factors for the health system. In our work the crucial dimension of health resilience that we focus on is shown in the efficiency drop coming from Syrians being countermanded by later health system reactions and adaptations, and the health level and utilization patterns of the Turkish population staying not significantly changed after, as before the Syrian refugee influx. All our regressions support the conclusion that although already existing health developments that are long-standing, current health investments to the secondary dimension of health are also important, the implementation of a truly universal primary healthcare reform has been most crucial in increasing the health of the Syrians without harming the health equilibrium of the Turkish population.

\section{Conclusion}

The research adds to the Turkish and international literature in the following ways:
The health service given to the Syrians is significant, and would constitute a non-negligible shock for important parts of the Turkish healthcare system. However the research doesn't only contribute to the immediate health shock literature that is focusing on communicable diseases [44], and acute crises [45], but also a wider research agenda which is prioritizing to conceptualize the changing responsiveness of health systems to new populations [46] and new health problems [47]. The ability to provide an adequate and sustainable healthcare for a new population of 3.3 million, with new health needs and new health demands is a very worthwhile process to learn from and to study.

The public health system shouldering ( 70 percent) the majority of the extra health cost, and service has been greatly beneficial, controlling the costs, and the internal prices for the vulnerable parts of the Syrian population (which is sizeable), and allowing an equity of service and access being provided to the Syrians vis-a-vis the Turkish population. Looking at the general literature it has been recognized that a greater public investment in health would ease the integration of refugees to society, with minimal problems for the domestic population [5]. Our research focuses on the specific investment to the primary healthcare side of the health economy. The implementation of the family health system has been greatly beneficial in the context of the Syrian influx, in cushioning the impact of the capacity overutilization for the Turkish population, and for the Turkish healthcare system to keep its core functions intact.

Although the universal primary healthcare provision has been relatively recent for the Turkish geography [48], the paper gives evidence for the fact that the rate of take-up (especially in the areas where Syrian arrivals have been highest as you can see in figure 2) is high enough so that Turkish primary healthcare utilization has protected against capacity problems in the secondary care dimension. This contributes to the worldwide UHC literature about the challenges and benefits of increasing health integration [49], in the specific case of refugee integration, which is an exceptional case, but a case that is a valuable and increasingly relevant exception.

The research also has underlined that the issues of macro access, over the period of 2011-2016, has largely been solved. What we need to investigate further is how the second stage process after 2016, where Syrians have access to their own primary healthcare facilities has worked. Data on this question of the overall health level of refugees suggests significant differences exist among the Syrian groups on many different social dimensions effecting health [50], suggesting that micro-targeting the vulnerable parts of the Syrian population is still a work in process.

The refugee effect, and refugee carrying limit literature is increasingly finding that as refugees leave their initial catchment areas, and integrate with the rest of the domestic population, thinking about the carrying capacity just from the perspective of Syrians is increasingly limiting, and unhelpful. What determines the ability of the system to integrate and cover refugees is increasingly a function of to what extent the domestic populations can be protected from the initial refugee demand effect in the different markets. Our research is crucial for highlighting the importance of a well functioning and trusted primary healthcare portion, targeting the domestic populations, in giving extra resilience characteristics to the healthcare system, and from a complimentary side, increasing the ability of the system to provide ever greater health integration to the refugee population, without damaging the health capital of the already existing domestic population.

In terms of the UHC (Universal Healthcare) introduction literature in the developing countries literature which has become intensely more 


\section{Appendix}

Table 7: Change in family healthcare utilization (from 2010 to 2016-weighted average) dependent on Syrian shock variable.

\begin{tabular}{|c|c|c|c|c|c|}
\hline $\begin{array}{c}\triangle P C \text { Utilization } \\
(2016-2010)\end{array}$ & Coef. & Std. Err. & $z$ & $P>z$ & $\begin{array}{l}\text { [95\% Conf. } \\
\text { Interval] }\end{array}$ \\
\hline Syrian shock & 2.31 & 1.12 & 2.06 & 0.039 & 0.1140 .52 \\
\hline $\begin{array}{l}\text { Year of } \\
\text { implementation }\end{array}$ & -9.1 & 5.17 & -1.76 & 0.079 & -32.7414 .44 \\
\hline Health factors & 11.71 & 18.110 & 0.65 & 0.518 & -23.7847 .21 \\
\hline _cons & 18.542 & 0.180 & 0.77 & 0.442 & -28.536 .56 \\
\hline $\begin{array}{c}\text { Random-effects } \\
\text { parameters }\end{array}$ & \multicolumn{2}{|c|}{ Estimate } & Std. Err. & \multicolumn{2}{|c|}{ [95\% Conf. Interval] } \\
\hline \multicolumn{6}{|l|}{ ibbs1: Identity } \\
\hline var(_cons) & \multicolumn{2}{|c|}{9445.96} & 5077.144 & \multicolumn{2}{|c|}{3294.05327087 .04} \\
\hline var(Residual) & \multicolumn{2}{|c|}{18703.14} & 3371.26 & \multicolumn{2}{|c|}{13136.6526628 .37} \\
\hline
\end{tabular}

LR test vs. linear model: chibar2 (01) $=15.71$ Prob $>=$ chibar2 $=0.0000$

Table 8: Change in family healthcare utilization (from 2012 to 2016-average) dependent on Syrian shock variable, conditional on satisfaction with prior family healthcare services.

\begin{tabular}{|l|c|c|c|c|c|}
\hline $\begin{array}{c}\text { APC Utilization } \\
\text { (2016-2012) }\end{array}$ & Coef. & Std. Err. & $\mathbf{z}$ & $\mathbf{P > z}$ & $\begin{array}{c}\text { [95\% Conf. } \\
\text { Interval] }\end{array}$ \\
\hline Syrian shock & 1.85 & 1.09 & $\mathbf{1 . 6 9}$ & 0.091 & -0.2944 .00 \\
\hline Health development & -1.230 & .91 & -1.35 & 0.176 & -3.035 .54 \\
\hline $\begin{array}{l}\text { Satisfaction of use } \\
\text { of P. care }\end{array}$ & 4.44 & 1.68 & $\mathbf{2 . 6 4}$ & 0.008 & 1.147 .74 \\
\hline Constant intercept & -6.36 & 3.60 & -1.77 & 0.077 & -13.426 .94 \\
\hline
\end{tabular}

\begin{tabular}{|l|l|l|l|}
\hline $\begin{array}{c}\text { Random-effects } \\
\text { parameters }\end{array}$ & Estimate & Std. Err. & [95\% Conf. Interval] \\
\hline ibbs1: Identity & & & \\
\hline var(_cons) & 9472.173 & 5136.959 & 3272.08927420 .42 \\
\hline var(Residual) & 17546.59 & 3002.496 & 12546.9724538 .43 \\
\hline
\end{tabular}

LR test $v s$. linear model: $\operatorname{chibar} 2(01)=7.22$ Prob $>=$ chibar $2=0.0000$

Table 9: Primary healthcare utilization change from 2010 to 2016-fullset of explanatory variables.

\begin{tabular}{|l|c|c|c|c|}
\hline $\begin{array}{l}\text { ( } \mathbf{(}) \text { Health Utilization-Primary Care } \\
\text { Doctor(2010-6) }\end{array}$ & Coef. & Std. Err. & $\mathbf{z}$ & $\mathbf{P}>\mathbf{z}$ \\
\hline $\begin{array}{l}\text { Satisfaction from primary care (2010- } \\
\text { 6) }\end{array}$ & 1.99 & 0.92 & 2.16 & 0.035 \\
\hline Syrian health shock & 1.295 & 0.57 & 2.26 & 0.027 \\
\hline Health factors & -5.24 & 10.47 & -0.50 & 0.618 \\
\hline Time length of primary care intro & 0.054 & 0.039 & 1.38 & 0.174 \\
\hline Gender ratio(M/F) & -1.48 & 2.44 & -0.61 & 0.546 \\
\hline Old over young D.Ratio & -2.36 & 3.52 & -0.67 & 0.505 \\
\hline Poverty index & -2.71 & .894 & -3.04 & 0.03 \\
\hline Urbanization & 0.87 & 1.33 & 0.65 & 0.515 \\
\hline Constant & -3.54 & 3.91 & -0.90 & 0.370 \\
\hline
\end{tabular}

Table 10: Change in emergency room utilization (from 2010 to 2016-weighted average) dependent on Syrian shock variable.

\begin{tabular}{|l|c|c|c|c|c|}
\hline $\begin{array}{c}\Delta \text { Emergency Room } \\
\text { Applications }\end{array}$ & Coef. & Std. Err. & $\mathbf{z}$ & $\mathbf{P > z}$ & $\begin{array}{c}\text { [95\% Conf. } \\
\text { Interval] }\end{array}$ \\
\hline Syrian shock & 0.156 & 0.051 & $\mathbf{3 . 0 6}$ & 0.002 & 0.0560 .256 \\
\hline Health development & -0.70 & 4.04 & -0.18 & 0.86 & -8.627 .21 \\
\hline Constant intercept & 0.40 & 2.67 & 0.15 & 0.88 & -4.845 .64 \\
\hline $\begin{array}{l}\text { Random-effects } \\
\text { Parameters }\end{array}$ & Estimate & Std. Err. & $\begin{array}{c}\text { [95\% Conf. } \\
\text { Interval] }\end{array}$ \\
\hline ibbs1: Identity & $4.91 \mathrm{e}-20$ & $5.58 \mathrm{e}-19$ & $1.04 \mathrm{e}-292.32 \mathrm{e}-10$ \\
\hline var(_cons) & 59.67848 & 9.436085 & $\begin{array}{c}43.77535 \\
81.35904\end{array}$ \\
\hline var(Residual) & & & &
\end{tabular}

LR test vs. linear model: chibar2(01) $=0.00$ Prob $>=$ chibar2 $=1.0000$.

Table 11: Change in emergency application proportion with IV-2 Stage ${ }^{1}$ methodology.

\begin{tabular}{|c|c|c|c|c|c|}
\hline $\begin{array}{c}E^{2} \text {. Proportion Increase } \\
(2016)\end{array}$ & Coef. & Std. Err. & $z$ & $P>Z$ & $\begin{array}{l}\text { [95\% Conf. } \\
\text { Interval] }\end{array}$ \\
\hline Time of PH.treatment ${ }^{3}$ & & 2 & -1.27 & 0.2 & $-5.07-0.43$ \\
\hline Syrian heal & 0.16 & 0.049 & 21 & 0 & 0.0640 .257 \\
\hline Primary care utili & cor & 0. & J.m & 0.001 & $-0.194-0.05$ \\
\hline Constant in & 5.13 & 2 & 1.9 & 0.05 & -0.16810 .43 \\
\hline
\end{tabular}

${ }^{1}$ The utilization of primary care is instrumented by prior health care factors (prior to the Syrians arriving), utility that the populations derived from the primary health care utilization, and the year of implementation variable, which assumes that with constant take-up rate, the provinces to pass to primary healthcare fast will have higher utilization rates in 2016. ${ }^{2}$ Emergency room applications.

${ }^{3}$ Primary healthcare reform introduction date, that is different for different provinces.

${ }^{4}$ The proportion of the increase in health applications (\%) as a result of the Syrian local demand, in terms of $\Delta$ between 2013 and 2016.

${ }^{5}$ Primary healthcare utilization in 2016.

Table 12: Change in emergency application proportion with IV-2 Stage ${ }^{1}$ methodology.

\begin{tabular}{|l|c|c|c|c|}
\hline$(\mathbf{\Delta})$ Vaccine Completion rate-Hepatit B & Coef. & Std. Err. & $\mathbf{Z}$ & $\mathbf{P}>\mathbf{Z}$ \\
\hline Health development & 3.09 & 3.14 & 0.98 & 0.329 \\
\hline Syrian health Shock (in \% term) & $\mathbf{0 . 3 7}$ & $\mathbf{0 . 1 8}$ & $\mathbf{2}$ & $\mathbf{0 . 0 5}$ \\
\hline Syrian effect *Primary health effect & $\mathbf{2 . 2}$ & $\mathbf{1 . 1}$ & $\mathbf{2}$ & $\mathbf{0 . 0 5}$ \\
\hline Average health supply index & 0.54 & 0.39 & 1.37 & 0.173 \\
\hline Gender Ratio(M/F) & -6.37 & 8.83 & -0.72 & 0.477 \\
\hline Old over young D. Ratio & -0.77 & 1.09 & -0.72 & 0.475 \\
\hline Poverty index & 0.138 & 0.293 & 0.48 & 0.635 \\
\hline Urbanization & 0.549 & 0.419 & 1.33 & 0.188 \\
\hline Constant & -4.38 & 8.81 & -0.49 & 0.625 \\
\hline
\end{tabular}

${ }^{1}$ The utilization of primary care is instrumented by prior health care factors (prior to the Syrians arriving), utility that the populations derived from the primary health care utilization, and the year of implementation variable, which assumes that with constant take-up rate, the provinces to pass to primary healthcare fast will have higher utilization rates in 2016. 
important in the second decade of the $21^{\text {st }}$ Century, our paper allows for a new perspective. The general goal of reaching the UHC is an area where Turkey's health system can offer significant achievements. This paper shows that such improvements is not only crucial for providing protection against adverse health shocks that the citizens' health can suffer, but also constitutes a crucial buffer which forms the health resilience of the overall system against adverse demand shocks coming from the unexpected refugee demand. The potential long term benefits of following and state-financing a UHC policy should not only be discussed vis-à-vis the nation's health outcomes [51], but should be discussed in line with the humanitarian need and priority to protect the refugees health and human capital levels. Turkish health policy research have recently focused on the importance and utility of UHC reform [52] and the socialized health reforms, but none of this has been discussed in the context of Syrian refugees, unlike other countries health literature [53].

The research adds to Turkish policy and its utility in the following ways: the advantages of following the right policies will be to create a sustainable path of integration for the already existing population that has arrived, and create a blueprint for the integration of the new populations that can arrive. International research has made it very clear that the geographies that are closest to Turkey (Middle East Delta in particular) will be increasingly un-inhabitable in large swathes in the next 50 years. Turkey's humanitarian priorities, and its geographical position, will mean that integration of these new populations will be increasingly on our agenda. In terms of deriving conclusions from our successes, health and public health is a very valuable literature, where Turkey and other countries can both use this as a learning experience for its own future policies, for the changing policies in the Middle East [54] and for the future of the world which will be defined by increasingly mobile populations, and significant health shocks.

\section{References}

1. Cherri Z, Arcos González P, Castro Delgado R (2016) The LebaneseSyrian crisis: impact of influx of Syrian refugees to an already weak state. Risk Manag Healthc Policy 9: 165-172.

2. Coutts A, Fouad FM, Batniji R (2013) Assessing the Syrian health crisis: the case of Lebanon. Lancet 381: e9.

3. Arastirmasi Sonuclari (2013) Türkiye Cumhuriyeti Başbakanlık, Afet ve Acil. In: Zeynep Şahin Mencütek (eds) Refugee Governance, State and Politics in the Middle East. Taylor \& Francis, UK.

4. Türk Tabipleri Birliği Yayınları (2016) Savaş, Göç Ve Sağlik. Turkey.

5. Doocy S, Lyles E, Hanquart B, LHAS Study Team, Woodman M (2016) Prevalence, care-seeking, and health service utilization for non-communicable diseases among Syrian refugees and host communities in Lebanon. Confl Health 10: 21.

6. Doocy S, Lyles E, Akhu-Zaheya L, Burton A, Burnham G (2016) Health service access and utilization among Syrian refugees in Jordan. Int J Equity Health 15: 1-15.

7. Ekmekci PE (2017) Syrian refugees, health and migration legislation in Turkey. J Immigr Minor Health 19: 1434-1441.

8. Merkezi OSA (2015) Effects of the Syrian refugees on Turkey (No. 195). Orsam Report.

9. Ammar W, Kdouh O, Hammoud R, Hamadeh R, Harb H, et al. (2016) Health system resilience: Lebanon and the Syrian refugee crisis. $J$ Glob Health 6: 020704.
10. Lapao LV, Silva A, Pereira N, Vasconcelos P, Conceicao C (2015) Ebola impact on African health systems entails a quest for more international and local resilience: the case of African Portuguese speaking countries. Pan Afr Med J 22: 15.

11. Lembani $M$, de Pinho $H$, Delobelle $P$, Delobelle $C$, Mathole $T$, et al. (2015) A Case Study of Maternal Health Service Provision in OR Tambo District, Eastern Cape, in the Context of Chronic Poor Health Performance. Report to the ReBUILD Consortium. New York, MSPH, Columbia University.

12. Thomas S, Keegan C, Barry S, Layte R, Jowett M, et al. (2013) A framework for assessing health system resilience in an economic crisis: Ireland as a test case. BMC Health Serv Res 13: 450.

13. McKenzie A, Abdulwahab A, Sokpo E, Mecaskey JW (2015) Building a Resilient Health System: Lessons from Northern Nigeria. IDS Working Paper 454.

14. Legido-Quigley H, Mateos-García JT, Campos VR, Gea-Sánchez M, Muntaner C, et al. (2020) The resilience of the Spanish health system against the COVID-19 pandemic. Lancet Public Health 5: e251-e252.

15. Kruk ME, Ling EJ, Bitton A, Cammett M, Cavanaugh K, et al. (2017) Building resilient health systems: a proposal for a resilience index. BMJ 357: j2323.

16. Hanefeld J, Mayhew S, Legido-Quigley H, Martineau F, Karanikolos $M$, et al. (2018) Towards an understanding of resilience: responding to health systems shocks. Health policy and planning 33: 355-367.

17. Kruk ME, Myers M, Varpilah ST, Dahn BT (2015) What is a resilient health system? Lessons from Ebola. Lancet 385: 1910-1912.

18. Kooli C (2020) Review of assisted reproduction techniques, laws, and regulations in Muslim countries. Middle East Fertil Soc J 24: 1-15.

19. Erdoğan M (2018) Suriyeliler Barometresi: Suriyelilerle Uyum İçinde Yaşamın Çerçevesi. Istanbul: İstanbul Bilgi Üniversitesi Yayınları, Istanbul, Turkey.

20. Döner P, Özkara A, Kahveci R (2013) Syrian refugees in Turkey: numbers and emotions. Lancet 382: 764

21. Ozaras R, Leblebicioglu H, Sunbul M, Tabak F, Balkan II, et al. (2016) The Syrian conflict and infectious diseases. Expert Rev Anti Infect Ther 14: 547-555.

22. Sahin E, Dagli TE, Acarturk C, Sahin Dagli F (2020) Vulnerabilities of Syrian refugee children in Turkey and actions taken for prevention and management in terms of health and wellbeing. Child Abuse Negl 104628.

23. DeJong J, Ghattas H, Bashour H, Mourtada R, Akik C, et al. (2017) Reproductive, maternal, neonatal and child health in conflict: a case study on Syria using Countdown indicators. BMJ Glob Health 2: e000302.

24. United Nations High Commissioner for Refugees (2017) Inter-Sector Working Group, Jordan: Protection Sector Quarterly Report (July 2017-September 2017). United Nations Office for the Coordination of Humanitarian Affairs, ìstanbul, Turkey.

25. Tappis H, Lyles E, Burton A, Jordan Health Access Study Team, Lebanon Health Access Study Team, et al. (2017) Maternal Health Care Utilization among Syrian Refugees in Lebanon and Jordan. Matern Child Health J 21: 1798-1807.

26. United Nations High Commissioner for Refugees (2017) Health Access and Utilization Survey among Syrian refugees in Lebanon. UNHCR, Geneva, Switzerland. 
27. Reese Masterson A, Usta J, Gupta J, Ettinger AS (2014) Assessment of reproductive health and violence against women among displaced Syrians in Lebanon. BMC Womens Health 14: 25

28. Refaat MM, Mohanna K (2013) Syrian refugees in Lebanon: facts and solutions. Lancet 382: 763-764.

29. Roberton T, Weiss W, Jordan Health Access Study Team, Lebanon Health Access Study Team, Doocy S (2017) Challenges in Estimating Vaccine Coverage in Refugee and Displaced Populations: Results from Household Surveys in Jordan and Lebanon. Vaccines (Basel) 5: 22.

30. Rossi R, Assaad R, Rebeschini A, Hamadeh R (2016) Vaccination Coverage Cluster Surveys in Middle Dreib-Akkar, Lebanon: Comparison of Vaccination Coverage in Children Aged 12 59 Months Pre-and Post-Vaccination Campaign. PloS one 11: e0168145-e0168145

31. His Excellency, Murshidi MM, Hijjawi MQ, Jeriesat S, Eltom A (2013) Syrian refugees and Jordan's health sector. Lancet 382: 206-207.

32. Lyles E, Hanquart B, LHAS Study Team, Woodman M, Doocy S (2016) Health service utilization and access to medicines among Syrian refugee and host community children in Lebanon. J Int Humanit Action. 1: 1-13.

33. Parkinson SE, Behrouzan O (2015) Negotiating health and life: Syrian refugees and the politics of access in Lebanon. Soc Sci Med 146: 324-331.

34. Johns Hopkins Bloomberg School of Public Health (2015) Syrian refugee and Affected Host Population Health Access Survey in Lebanon.

35. Benage M, Greenough PG, Vinck P, Omeira N, Pham P (2015) An assessment of antenatal care among Syrian refugees in Lebanon. Confl Health 9: 8.

36. Güngör A, Akman AÖ, Karagö C, Koçoğlu M, Çakır BÇ, et al. (2019) Evaluation of Health Care Services Delivered to Syrian Refugees in a Tertiary Pediatric Hospital Between 2013-2016. Sakarya Med J 9: 46-51

37. Zencir ve M, Davas A (2014) Suriyeli Sığınmacılarve Sağlık Hizmetleri Raporu. Türk Tabipler Birliği, Turkey.

38. Aygün O, Gökdemir Ö, Bulut Ü, Yaprak S, Güldal D (2016) Evaluation of Primary Health Care Services Which is provided to Refugees within a Public Health Center. Turk J Fam Med Prim Care 10: 6-12.

39. Dionigi $F(2016)$ The Syrian refugee crisis in Lebanon: State fragility and social resilience. LSE Middle East Centre Paper Series 15 London, UK.

40. The World Bank, Republic of Turkey Ministry of Health (2012) Turkey Health System Performance Assessment 2011. World Health Oraganization, Europe.
41. Republic of Turkey (2016a) Healthcare Utilization, Facilities and Health Professionals-Yearly Statistics 2009-2016. Ankara, Turkey: Health Systems Research and Development Department, Directorate General of Health Research, Ministry of Health, Turkey.

42. Turk Stat (2016) Yasam memnuniyeti arastirmasi nin uygulama yöntemi, tanim ve kavramlar. Turkish Statistical Institute.

43. Wulff K, Donato D, Lurie N (2015) What is health resilience and how can we build it? Annu Rev Public Health 36: 361-374.

44. Blanchet K, Ramesh A, Frison S, Warren E, Hossain M, et al. (2017) Evidence on public health interventions in humanitarian crises. Lancet 390: 2287-2296.

45. Nolan A, Barry S, Burke S, Thomas S (2014) The impact of the crisis on the health system and health in Ireland. World Health Organization, European Observatory on Health Systems and Policies.

46. Mortensen A (2011) Public health system responsiveness to refugee groups in New Zealand: activation from the bottom up. Soc Policy J New Zealand 37: 1-12.

47. Atun R, Jaffar S, Nishtar S, Knaul FM, Barreto ML, et al. (2013) Improving responsiveness of health systems to non-communicable diseases. Lancet 381: 690-697.

48. Hone T, Gurol-Urganci I, Millett C, Başara B, Akdağ R, et al. (2017) Effect of primary health care reforms in Turkey on health service utilization and user satisfaction. Health Policy Plan 32: 57-67.

49. Carrin G, Mathauer I, Xu K, Evans DB (2008) Universal coverage of health services: tailoring its implementation. Bull World Health Organ 86: 857-863.

50. Bilukha OO, Jayasekaran D, Burton A, Faender G, King'ori J, et al. (2014) Nutritional status of women and child refugees from SyriaJordan, April-May 2014. MMWR Morb Mortal Wkly Rep 63: 638 639.

51. Cesur R, Güneş PM, Tekin E, Ulker A (2017) The value of socialized medicine: The impact of universal primary healthcare provision on mortality rates in Turkey. J Public Econ 150: 75-93.

52. World Bank (2013) Turkey: Performance-based contracting scheme in family medicine-design and achievements. The World Bank, Washington DC, USA 77029-TR.

53. Blanchet K, Fouad FM, Pherali T (2016) Syrian refugees in Lebanon: the search for universal health coverage. Confl Health 10: 12.

54. Achour N, Price ADF (2010) Resilience strategies of healthcare facilities: present and future. Int J Disaster Resil Built Environ 1: 264 276 